\title{
Annealing and Normalizing of AISI 1045 Steel: A Lamellae Analysis
}

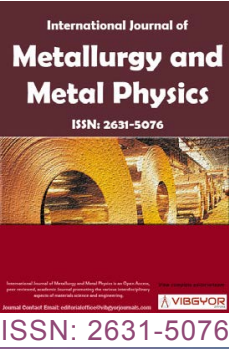

\section{AL Yánez, EA Narváez, LF Salinas and EA Bonifaz*}

Department of Mechanical Engineering, Universidad San Francisco de Quito, Ecuador

\begin{abstract}
Two heat treatments, annealing and normalizing were conducted to verify the alteration of the microstructure and corresponding mechanical properties of AISI 1045 steel. The effect of cooling rate in the heat treatment process on the lamellae microstructure (lamellar thickness) and hardness it was studied. Results show reduced lamellar thickness of $0.175 \mu \mathrm{m}$ in the normalized condition (high cooling rate-fine pearlite) than in the annealed condition of 0.294 $\mu \mathrm{m}$ (low cooling rate-coarse pearlite). Using the Vickers Hardness Tester, it was determined that the hardness of AISI 1045 steel in the annealed condition and normalized condition is 56.42 HV and $202 \mathrm{HV}$, respectively.
\end{abstract}

\section{Keywords}

Hypoeutectoid steel, Phase transformations, Heat treatment, Normalizing, Annealing, Pearlite, Lamellar thickness

\section{Introduction}

Several of the various microstructures that may be produced in steel alloys depends on both the carbon content and heat treatment. Mechanical properties of metals can be altered by a number of techniques. One of the most convenient methods to introduce phase changes is heat treatment as the cooling rate has an influence in the resultant phase. Heat treatment refers to several types of heating and cycles performed on a metal to beneficially change its properties. They operate by altering the basic microstructure of the metal, which in turn determines mechanical properties [1]. Of all binary alloy systems, the one that is possibly the most important is that for iron and carbon. The develop- ment of a set of desirable mechanical characteristics in steels are accomplished by an appropriate heat treatment. Steel varies its phases depending on composition and temperature. A variety of phase transformations are important in the processing of materials, and usually they involve some alteration of the microstructure. The absolute layer thickness of the ferrite and cementite depends on the temperature (and cooling rate) at which the transformation is allowed to occur. At temperatures just below the eutectoid, relatively thick layers of both the $\alpha$-ferrite and $\mathrm{Fe}_{3} \mathrm{C}$ phases (i.e., the coarse pearlite) are produced (See Figure 1). At these temperatures, diffusion rates are relatively high, such that carbon atoms can diffuse relatively long distances, which results in the formation of thick lamellae [2].

*Corresponding author: EA Bonifaz, Department of Mechanical Engineering, Universidad San Francisco de Quito, Diego de Robles y Av. Pampite 170901, Cumbayá, Ecuador

Accepted: May 13, 2020; Published: May 15, 2020

Copyright: (C) 2020 Yánez AL, et al. This is an open-access article distributed under the terms of the Creative Commons Attribution License, which permits unrestricted use, distribution, and reproduction in any medium, provided the original author and source are credited.

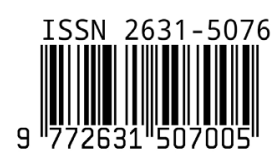

Yánez et al. Int J Metall Met Phys 2020, 5:053 


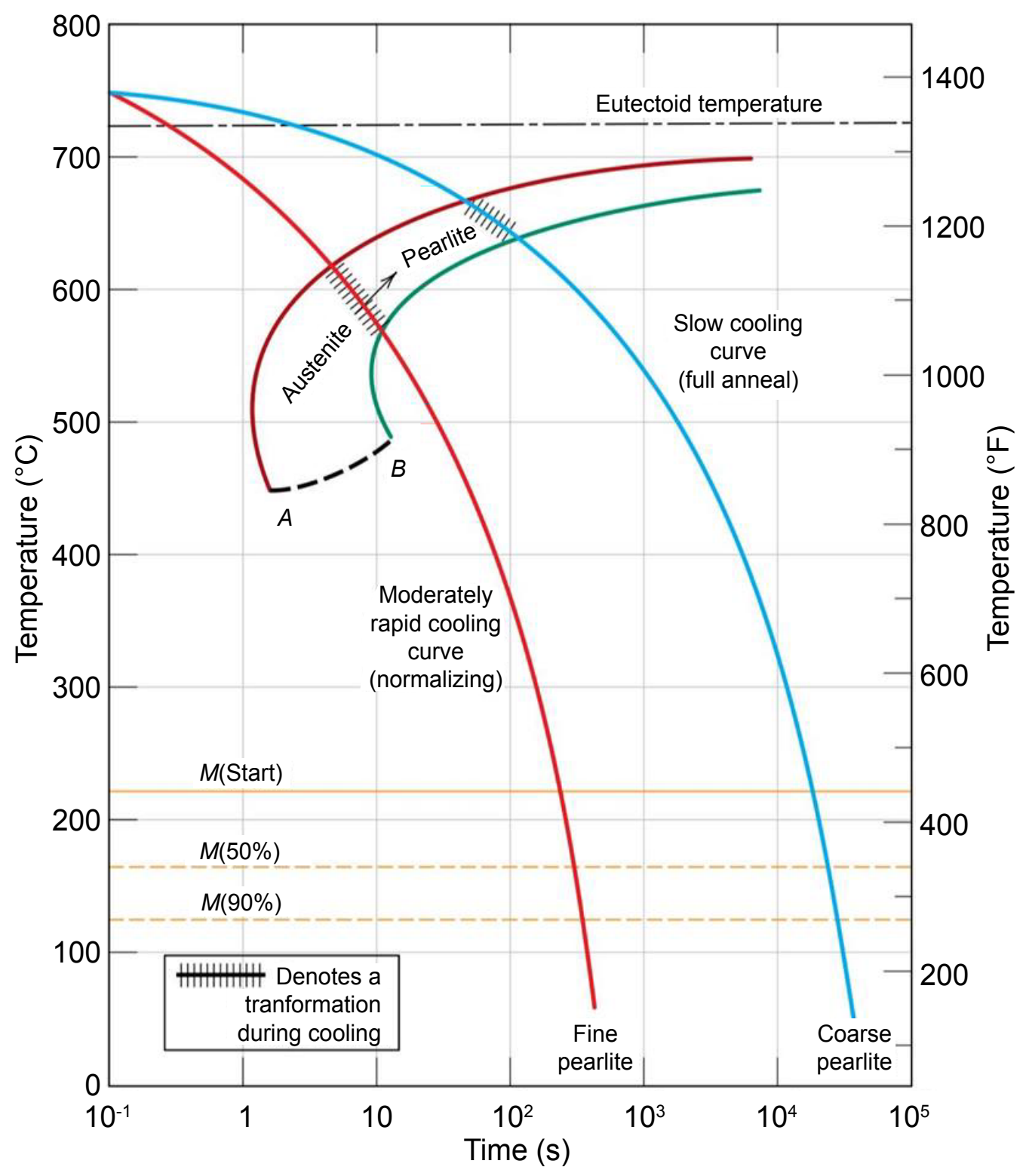

Figure 1: Moderately rapid and slow cooling curves superimposed on a continuous-cooling transformation diagram for eutectoid steel (after Ref. [2]).

With decreasing temperature, the carbon diffusion rate decreases, and the layers become progressively thinner. The thin-layered structure produced in the vicinity of $540{ }^{\circ} \mathrm{C}$ is termed fine pearlite.

The continuous cooling transformation (CCT) diagram shown on Figure 1, is a plot of temperature versus the logarithm of time for a steel alloy of definite composition. Used to indicate when transformations occur as the initially austenitized material is continuously cooled at a specific rate; in addition, the final microstructure and mechanical characteristics may be predicted. The CCT diagram describes more efficiently the resultant phases of normalizing and annealing. Figure 1 indicates that for a moderately rapid cooling (normalizing), the resultant phase is fine pearlite in which the alternating ferrite and cementite layers are relatively thin. Likewise, in full anneal (i.e., a slow cooling curve), coarse pearlite is formed. In coarse pearlite, the alternating ferrite and cementite layers are relatively thick. As the cooling rate decreases, the thickness and interlamellar spacing increases. Pearlite coarsening is part of the heat treatment with slow cooling that reflects higher nucleation and growth.

Heat treatments are related with cooling rates (See Figure 1 and Figure 2). Annealing is the process in which a material is heated to a critical temperature $T c$ for an extended period of time and then 


\section{Temperature vs. Time}

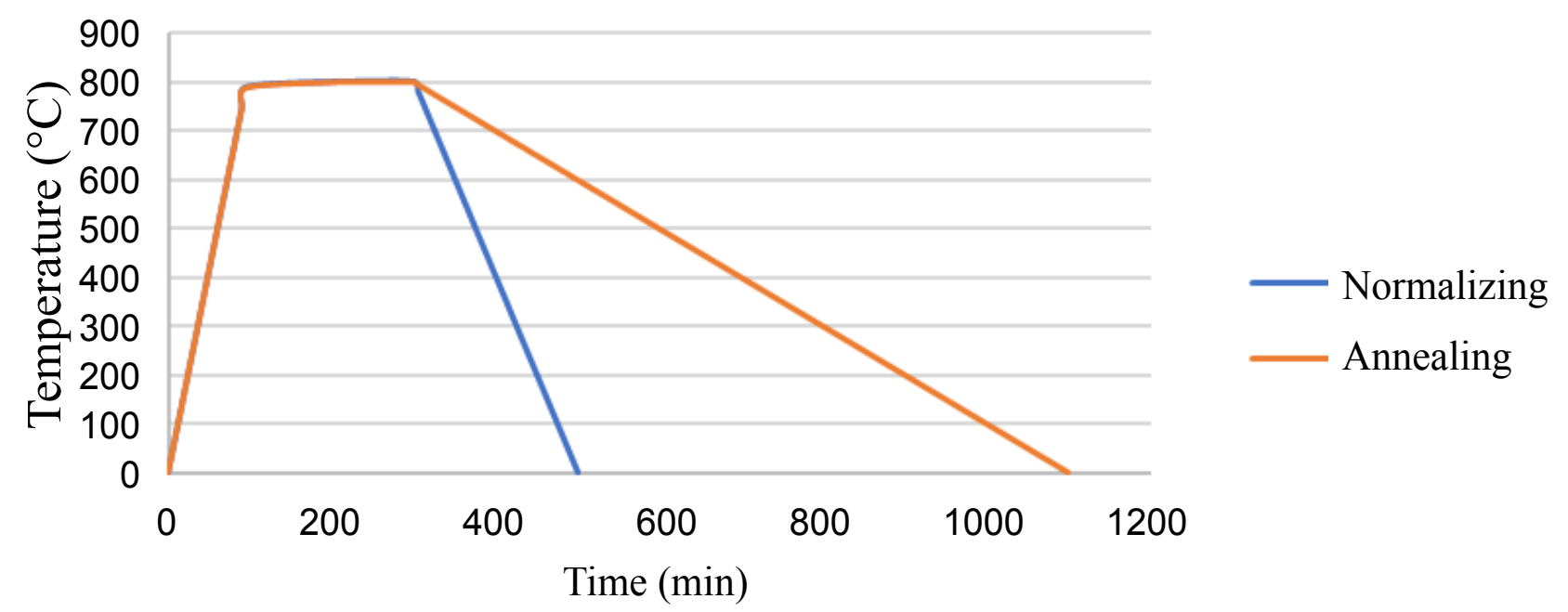

Figure 2: The heat treatment process. The cooling rate for the normalizing is calculated as $4{ }^{\circ} \mathrm{C} / \mathrm{min}$ and for the annealing as $1^{\circ} \mathrm{C} / \mathrm{min}$.

slowly cooled in the same atmosphere (furnace) to room temperature. The temperature in this process is maintained for larger periods of time and preserves energy for the microstructure to grow. Normalizing on the other hand is accomplished by heating to a critical temperature $T c$ for an extended period of time and cooling in air to room temperature. It refines grains (decrease the average grain size) and produces a more uniform distribution. It also relieves stresses, increases softness, ductility and toughness.

The mechanical properties are directly related to the microstructure, which in turn depends on the cooling rate experienced by the alloy. In consequence, as the cooling rate differs in the annealing and in the normalizing process, the hardness will adjust as well. A lot of work had been done to study the lamellae microstructure formed during an isothermal transformation in eutectoid steels. Contrary, a few works has been done to study the lamellae microstructure formed in continuous cooling transformation in hypoeutectoid steels. In annealing, particle growth occurs by long-range atomic diffusion [2]. Consequently, the growth rate is determined by the rate of diffusion which depends on the temperature. Moreover, the time dependence of rate, or kinetics, is important in the heat treatment since the reaction of fraction that has occurred is a function of time while temperature is maintained constant. Isothermal and continuous cooling transformation diagrams relate both temperature and time dependence of the transformation and are helpful in the determination of the resulted phase. Cooling hypoeutectoid steel first nucleates proeutectoid ferrite preferentially at austenite grain corners, followed by edges and then boundaries [3]. In this work, a discussion of the dependence of mechanical properties on lamellar thickness in the annealing and normalizing heat treatment processes is presented.

\section{Results and Discussion}

Mechanical and other properties of many materials depend on their microstructures, which are often produced as a result of phase transformations. The purpose of this research was to determine the effect of cooling rate in the heat treatment process on the lamellae microstructure and hardness of AISI 1045 steel. Following the recommendations of ASTM standards, several specimens were heat treated, polished and etched in order to analyze the interlamellar spacing and hardness of the final microstructure. The basic kinetic principles of solid-state transformations were applied in terms of the relationships between heat treatment, the development of microstructure, and mechanical properties. Two heat treatments, annealing and normalizing were conducted to verify the alteration of the microstructure and corresponding mechanical properties.

In the annealing process, the specimens were austenitizing above the upper critical tempera- 


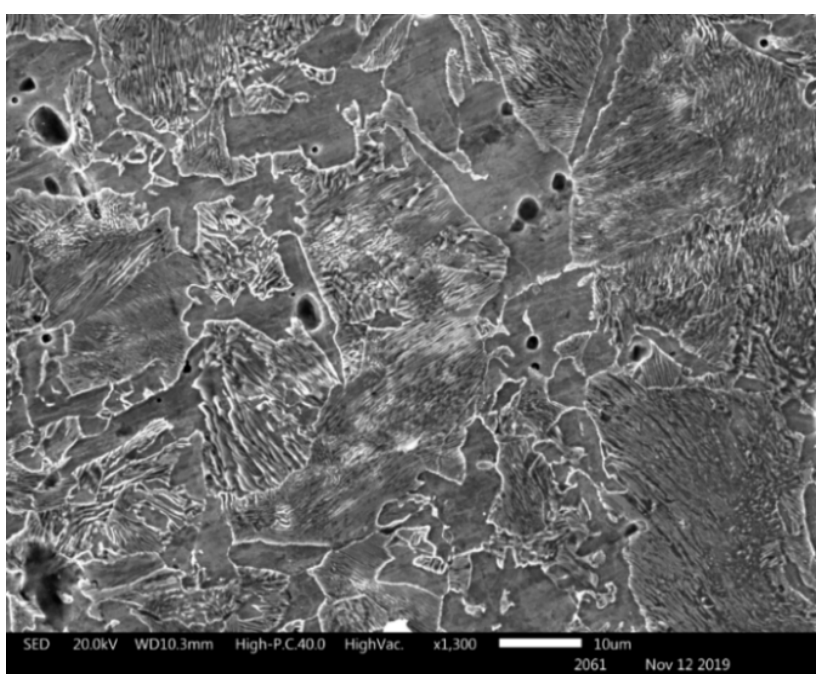

a)

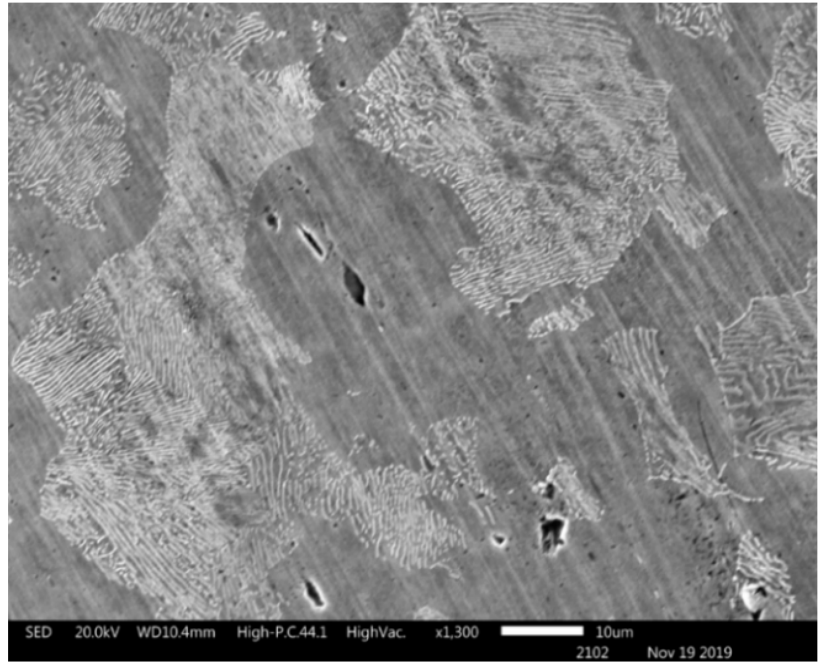

b)

Figure 3: Photomicrographs of: a) Fine pearlite; and b) Coarse pearlite. 1300X.

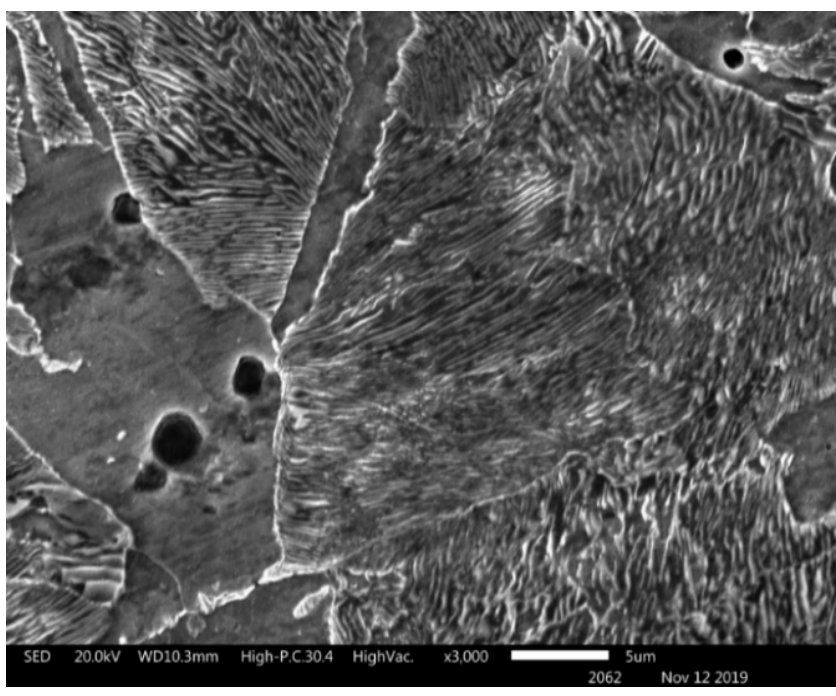

a)

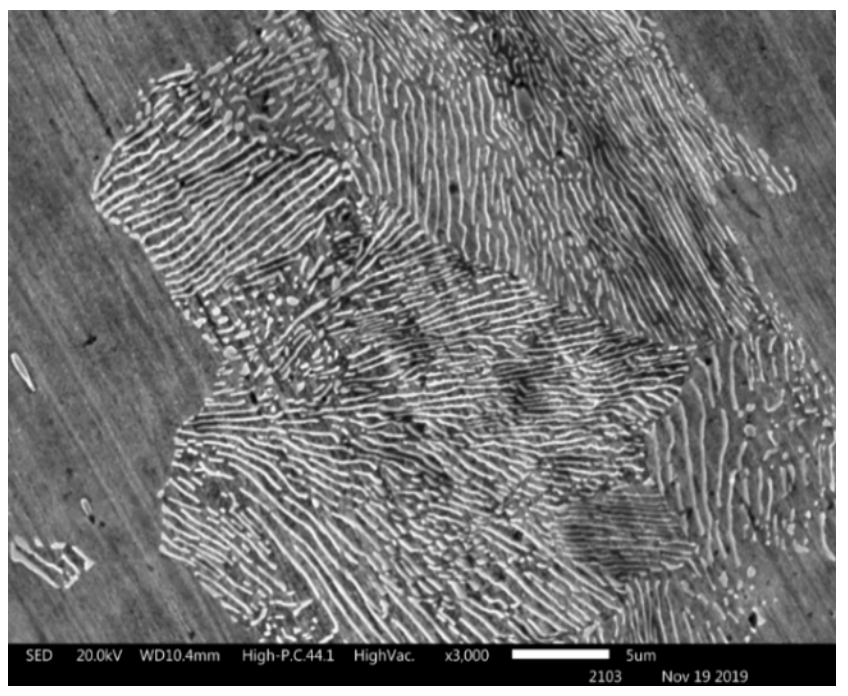

b)

Figure 4: Photomicrographs of: a) Fine pearlite; and b) Coarse pearlite. 3000X.

ture $\left(T C=800{ }^{\circ} \mathrm{C}\right)$, kept for 4 hours, and left into the furnace for approximately 10 hours. In the normalizing process, the specimens were austenitizing above the upper critical temperature $\left(T c=800^{\circ} \mathrm{C}\right)$, kept for 4 hours, and then cooling in air. The objective of this heat treatment is to enhance toughness by refining the grain size. The cooling rate for the normalizing depended on the surrounded air at room temperature while the cooling rate for the annealing depended on the heated air inside the furnace until it reached room temperature. The cooling rate for the normalizing is calculated as 4 ${ }^{\circ} \mathrm{C} / \mathrm{min}$ and for the annealing is $1^{\circ} \mathrm{C} / \mathrm{min}$. Once the steel specimens were treated, they were prepared according the ASTM E3-01 [4] and ASTM E407-07 [5] standards for SEM observations. Interlamellar structure can be clearly observed at different magnifications. Figure 3, Figure 4 and Figure 5 show scanning electron photomicrographs at $1300 \mathrm{X}$, $3000 X$ and $20000 X$ magnifications respectively. Regions having the alternating light and dark lamellar structure are pearlite; the dark and light layers in the pearlite correspond, respectively, to ferrite and cementite phases. To get mechanical information of the lamellae microstructure, hardness measurements were taken with a Vickers Scale of 0.3 as suggested by the ASTM E384-99 [6] standard.

By using the software ImageJ [7], the average 


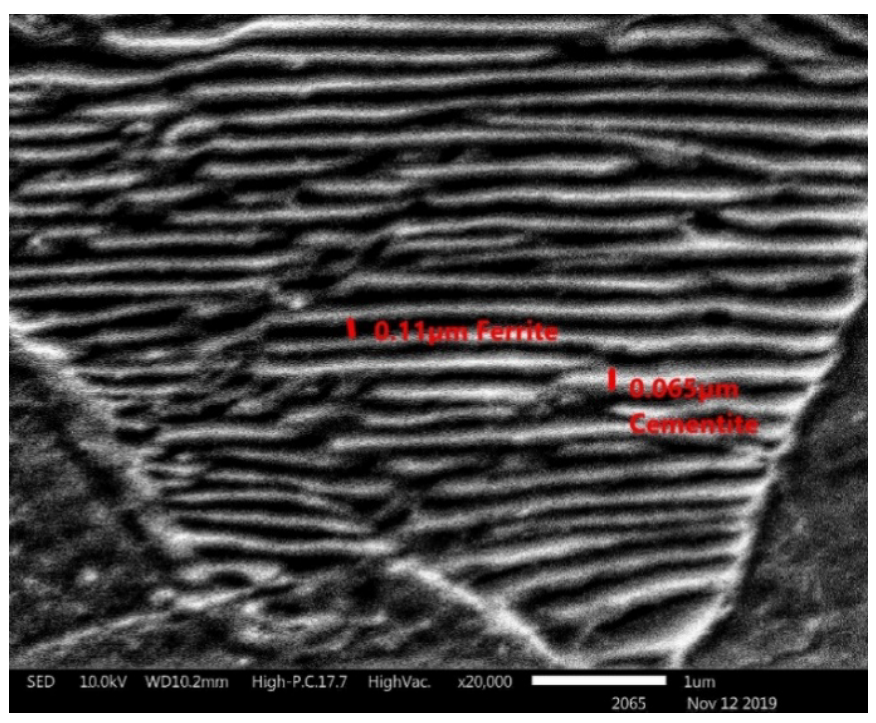

a)

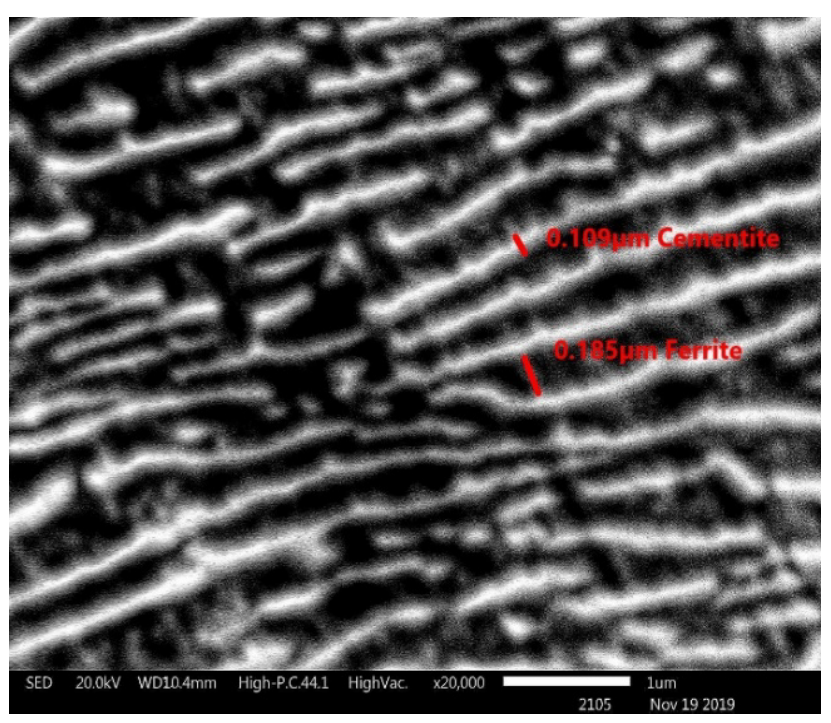

b)

Figure 5: Photomicrographs of: a) Fine pearlite; and b) Coarse pearlite. 20000X.

Table 1: Average thickness and average hardness of the studied lamellar microstructures.

\begin{tabular}{|l|l|l|l|l|}
\hline & $\begin{array}{l}\text { Ferrite thickness } \\
(\boldsymbol{\mu m})\end{array}$ & $\begin{array}{l}\text { Cementite } \\
\text { thickness }(\boldsymbol{\mu m})\end{array}$ & $\begin{array}{l}\text { Lamellar } \\
\text { thickness }(\boldsymbol{\mu m})\end{array}$ & Hardness HV 0.3 \\
\hline Normalizing (fine pearlite) & $0.11 \pm 0.0258$ & $0.065 \pm 0.027$ & 0.175 & $202 \pm 18.7$ \\
\hline Annealing (coarse pearlite) & $0.185 \pm 0.0717$ & $0.109 \pm 0.0247$ & 0.294 & $56.42 \pm 2.7$ \\
\hline
\end{tabular}

thickness at a magnification of 20000X was measured in normalized and annealed heat treated specimens. Values shown on Figure 5 and Table 1 reveal that the microstructural and mechanical features are in agreement with the basic kinetic principles of solid-state transformations. The thickness was almost doubled in annealing. Indeed, it affected the hardness as shown on Table 1. Annealing is used to eliminate residual stresses left from a previous process. In metals, this process "restores" a material through the elimination of dislocations from plastic deformation by inducing recrystallization. This process can be divided into three processes: Recovery, recrystallization, and grain growth. Dislocation density decreases significantly during recrystallization effectively eliminating any prior strain hardening. A significant movement of atoms occurs because the annihilation of dislocations density happens, and therefore, the hardness is considerably reduced [8]. Contrary, the higher hardness observed in the normalized condition (fine pearlite) is due to the presence of existing high dislocations density. These dislocations limit the space and free movement of atoms.

The annealing and normalizing of AISI 1045 Steel are compared in the present work. As documented on Figure 5 and Table 1, the thickness of ferrite and cementite in the annealed condition is bigger than in the normalized condition. It explains the lower hardness found in the annealed tested specimens. Quantified results demonstrate a strong dependence of flow stress (hardness) on phase type. The results are in agreement with the expected output that the flow resistance is higher for structures composed of finer and homogeneously distributed interlamellar aggregates. That is, hardness increases as grain size decreases when the metal undergoes a fast cooling rate. The microstructure is clearly shown by SEM, and the coarse or fine pearlite can explain those two specimens after different heat treatments.

\section{Conclusions}

1. It was verified that the resultant lamellar thickness is smaller in the normalized condition than in the annealed condition. The lamellar thickness in the normalized condition (high cooling rate-fine pearlite) is $0.175 \mu \mathrm{m}$, and in the annealed condition (low cooling rate-coarse pearlite) is $0.294 \mu \mathrm{m}$. 
2. Using the Vickers Hardness Tester, it was determined that the hardness of the AISI 1045 steel in the annealed condition and normalized condition is $56.42 \mathrm{HV}$ and $202 \mathrm{HV}$, respectively. This corresponds to the fact that hardness increases as grain size decreases when the metal undergoes a fast cooling rate.

3. The results are in agreement with the expected output that the flow resistance (hardness) is higher for structures composed of finer and homogeneously distributed interlamellar aggregates.

4. The effects of microstructural features upon the aggregate local mechanical response are clearly observed.

\section{Acknowledgment}

The metallographic assistance of Professor of Practice Marco Leon at the Materials and Manufacturing Group at Universidad San Francisco de Quito is greatly acknowledged.

\section{References}

1. Groover M (2013) Fundamentals of modern manufacturing: Materials, process, and systems. Danvers, John Wiley \& Sons.

2. Callister W, Rethwisch D (2014) Materials Science and Engineering: An Introduction. Hoboken, Wiley.

3. Kral MV (2012) Proeutectoid ferrite and cementite transformations in steels. Woodhead Publishing Series in Metals and Surface Engineering, 225-275.

4. (2004) Standard test methods for rockwell hardness and rockwell superficial hardness of metallic materials. ASTM E18-03, ASTM International, USA.

5. (2017) Standard guide for preparation of metallographic specimens. ASTM E3-01, ASTM International, USA.

6. (2015) Standard practice for microetching metals and alloys. ASTM E407-07, ASTM International, USA.

7. Image J Program: An open source image processing program. National Institute of Health (NIH).

8. Bonifaz EA, Richards NL (2008) The plastic deformation of non-homogeneous polycrystals. Int J Plasticity 24: 289-301. 